với dưới hoành trái, đô dày trung bình của liềm hơi là $3.5 \mathrm{~mm}$. Nguyễn Thị Mai Sương và CS (2014) cũng cho thấy liềm hơi gặp nhiều hơn ở bên phải (chiếm 42.5\%)[2]. Trong nghiên cứu này, chỉ có 3 trường hợp trong tổng số 23 bệnh nhân được thực hiện siêu âm ổ bụng được phát hiện có khí tự do trong ổ bụng. Về dấu hiệu này, tỷ lệ phát hiện có khí tự do nhờ siêu âm chẩn đoán thấp hởn nhiều so với các nghiên cứu của các tác giả đã công bố trước đó[4]. Tại Việt Nam, việc tìm kiếm dấu hiệu tràn khí tự do ổ bụng trong các trường hợp bệnh nhân bị nghi ngờ có thủng tạng rỗng chưa thực sự được các bác sỹ siêu âm quan tâm nhiều, chính vì vậy việc phát hiện dấu hiệu này còn hạn chế trong thực hành lâm sàng. Nhiều nghiên cứu trước đây đã cho thấy, siêu âm ổ bụng có thể chẩn đoán chính xác tràn khí màng bụng nhưng cũng không nên xác định siêu âm là phương pháp thăm khám duy nhất để chẩn đoán xác định hay loại trừ tràn khí màng bụng[4,5].

\section{KẾT LUÂ̂N}

Qua nghiên cứu 31 trường hợp thủng tạng rỗng tại Bệnh viện Hữu nghị Việt Đức, chúng tôi ghi nhận được một số kết luận như sau:

Thủng tạng rỗng gặp chủ yếu ở nam giới, nguyên nhân hay gặp nhất là do thủng ổ loét dạ dày-tá tràng. Trên $x$ quang, hình liềm hơi dưới hoành chỉ số ít các trường hợp và đa phần thấy ở dưới vòm hoành phải. Tuy nhiên, trên cắt lớp vi tính ổ bụng, có thể quan sát thây hơi ngoài lòng ống tiểu hoá ở phần lớn các trường hợp và có thể thấy thuốc cản quang thoát ra khỏi ống tiêu hoá nếu sử dụng phối hợp thuốc cản quang đường uống. Trên siêu âm, dấu hiệu đặc hiệu là hình ảnh "rèm cửa" ở mặt trước gan, tuy nhiên dẫu hiệu này cũng ít quan sát thấy.

\section{TÀl LIẸU THAM KHẢO}

1. Hoàng, N., N.N. Thắng, and Đ.V. Thời; Đánh giá kết quá phẫu thuật nội soi khâuu lỗ thung dạ dày - tá tràng tại bệnh viện Đà Nắng. Tạp chí khoà học, 2010. 63: p. 63-69.

2. Sương, N.T.M. and L.Đ. Phong;, Đăc điểm lâm sàng và hình ảnh Xquang thường qui ở bệnh nhân thủng tạng rỗng điêu trị tại bệnh viện Đa khoa Trung ương Cần Thớ Tạp chí y học thực hành, 2013. 9(879): p. 65-68.

3. Tiệp, N.V. and Đ.V.D. ; , Chẩn đoán và điều trị tổn thương tạng rống trong chấn thương bụng kín tại bệnh viện Quân y 103. Tạp chí y dược học quân sư 2018. 9: p. 161-167.

4. Jiang, L., J. $\mathbf{W u}$, and $X$. Feng, The value of ultrasound in diagnosis of pneumoperitoneum in emergent or critical conditions: A meta-analysis. Hong Kong Journal of Emergency Medicine, 2018. 26(2): p. 111-117.

5. Grechenig, W., et al., Detection of pneumoperitoneum by ultrasound examination: an experimental and clinical study. Injury, 1999. 30(3): p. 173-8.

\title{
MộT SỐ YẾU Tố SẢN KHOA LIÊN QUAN TỬ VONG SƠ SINH SỚM Ở TRẺ ĐẺ NON 28 - 32 TUẦ
}

\section{TÓM TẮT}

Mục tiêu: Nhận xét một số yếu tố sản khoa liên quan tử vong sơ sinh sớm ở trẻ đẻ non 28 - 32 tuần. Đối tượng và phương pháp nghiên cứu: Nghiên cứu mô tả cắt ngang trến những trẻ đẻ ra sống ở các trường hợp đơn thai có tuổi thai từ $28^{0 / 7}$ tuần đến hết 320/7 tuần tại Bệnh viện Phụ sản Trung ương trong khoảng thời gian từ 01/07/2020 đến 31/12/2020. Kểt quả: Trong số 238 trường hợp sinh non có 11 trẻ tử vong trong tuần đâu (chiếm tỷ lệ 4,62\%), phân lớn tử vong trong 24 giờ đầu tiên ( $5 / 11$ ca, chiếm 45,45\%). Những nguyên nhân hàng đâuu dẫn tới tử vong ở trẻ là

\section{${ }^{1}$ Đại học Y Hà Nội}

Chịu trách nhiệm chính: Dương Quỳnh Anh

Email: quynhanha4@gmail.com

Ngày nhận bài: 2.6.2021

Ngày phản biện khoa học: 31.7.2021

Ngày duyệt bài: 9.8.2021

\section{Dương Quỳnh Anh' ${ }^{1}$, Phạm Thị Thanh Hiền' ${ }^{1}$}

suy hô hấp (55\%), nhiễm khuẩn $(18 \%)$, xuất huyết não - màng não (18\%). 81,82\% (9/11 ca) trẻ tử vong có me mắc ít nhất một bệnh lý nội khoa hoặc sản khoa, làm tăng khả năng tử vong gấp gần 8 lần ( $O R=$ 7,96, KTC 95\% 1,68 - 37,71), cụ thể rối loạn huyết áp làm tăng gấp 6,3 lần $(\mathrm{OR}=6,37, \mathrm{KTC} 95 \% 1,84-$ $21,98)$. Đồng thời hậu quả thai chậm phát triển trong tữ cung cũng là yếu tố sản khoa làm tăng khả năng tử vong gấp 8,8 lần ( $\mathrm{OR}=8,89$, KTC $95 \% 2,54-31,12$ ). Kết luận: Me bệnh lý (đặc biệt rối loạn huyết áp) và thai chậm phát triển trong tử cung là các yếu tố làm tăng nguy cơ tử vong sơ sinh sớm của trẻ.

Tư khóa: đẻ non, tử vong sơ sinh, yếu tố nguy cơ

\section{SUMMARY}

OBSTETRIC RISK FACTORS FOR EARLY
NEONATAL DEATH IN PREMATURE
INFANTS BORN BETWEEN 28 TO 32
WEEKS' GESTATION

Objective: To analyze several obstetric risk 
factors for early neonatal death in premature babies born between 28 to 32 weeks' gestation. Subjects and method: This cross-sectional study include singleton live infants born between 28 to 32 weeks of gestation at National hospital of Obstetrics and Gynecology from July $1^{\text {st }} 2020$ to December $31^{\text {st }} 2020$. Results: Out of 238 singleton live births in the study, 11 infants died in the first week $(4,62 \%)$, the majortiy of deaths happened in the first 24 hours (5/11 cases, $45,45 \%)$. The leading causes are respiratory failure $(55 \%)$, infection $(18 \%)$, intraventricular hemorrhage $(18 \%) .81,82 \%$ ( $9 / 11$ cases) of child had mothers with health problems, increasing the probability of early neonatal death nearly 8 times (OR $=7,96,95 \%$ CI $1,68-37,71)$, particularly blood pressure disorders increase 6,3 times (OR $=6,37,95 \%$ CI 1,84-21,98). Preterm babies with intrauterine growth restriction were simutaneously 8,8 times more likely to die in the first week of life (OR $=8,89,95 \%$ CI 2,54-31,12). Conclusions: Maternal diseases (especially blood pressure problems) and intrauterine growth restriction were associated with increased risk of early neonatal mortality.

Keywords; preterm, neonatal death, risk factors

\section{I. ĐĂT VẤN ĐỀ}

Đẻ non được định nghĩa là khi cuộc sinh diễn ra ở tuần tuổi thai từ $22^{0 / 7}$ đến $36^{6 / 7}$ tuần [1]. Những biến chứng trực tiếp của đẻ non là nguyên nhân hàng đầu của tử vong sơ sinh hàng năm trên toàn câu. Trong vòng 28 ngày đầu đời, tỷ lệ tử vong cao nhất rơi vào tuần đầu tiên (được định nghĩa là tử vong sơ sinh sớm), lên đến $75 \%$ theo ước tính của Tổ chức $\mathrm{Y}$ tế Thế giới (WHO) [2]. Chiến lược hiện nay là sự song hành giữa nô lực giảm tỷ lệ đẻ non và nâng cao các hổ trợ y khoa để giảm thiểu các biến chứng của đẻ non, bởi $70 \%$ trường hợp tử vong sơ sinh sớm do nguyên nhân và các yếu tố nguy cơ có thể phòng ngừa được [2]. Trẻ đẻ càng non tháng, biến chứng càng nhiều và thậm chí ảnh hưởng lâu dài bởi sự thiếu trưởng thành của nhiêu cơ quan. Từ tuần 28 trở đi, khả năng sống của trẻ lên đến $92-98 \%$ [1]. Do vậy, nghiên cứu của tôi tập trung vào nhóm trẻ rất non tháng (28 - 32 tuần) là nhóm trẻ có khả năng sống cao nếu nhận được sự chăm sóc tích cực. Tại Việt Nam, các biện pháp tích cực để cải thiện tiển lượng sống của trẻ đẻ non có thể kể đến liệu pháp corticoid trước sinh, tuy nhiên vai trò của các yếu tố khác tác động lên khả năng sống sót của trẻ lại chưa được tìm hiểu sâu. Vì vậy chúng tôi tiến hành đề tài "Một số yếu tố sản khoa liên quan tử vong sơ sinh sớm ở trẻ đẻ non 28 - 32 tuân" với mục tiêu nhận xét một vài yếu tố ảnh hưởng lên khả năng sống của trẻ trong nhóm tuổi này.
II. ĐỐI TƯỢNG VÀ PHƯƠNG PHÁP NGHIÊN CỨU

2.1. Đối tượng nghiên cứu. Nghiên cứu được thực hiện tại Bệnh viện Phụ sản Trung ương trên các trẻ đẻ ra sống ở các trường hợp đơn thai có tuổi thai từ $28^{0 / 7}$ tuần đến hết $32^{0 / 7}$ tuần từ 01/07/2020 đến 31/12/2020.

Những trường hợp song thai có 1 thai chết lưu, trường hợp có chỉ định đình chỉ thai nghén do thai dị dạng, dị tật bẩm sinh, thai chết lưu không được chọn vào nghiên cứu.

\subsection{Phương pháp nghiên cứu}

Nghiên cứu mô tả cắt ngang.

Lấy thông tin về trẻ đẻ non và sản phụ thỏa mãn tiêu chuẩn lựa chọn sau một tuần đầu sau sinh. Những trẻ có thời gian sống dưới 7 ngày tuổi (tử vong sơ sinh sớm) được xếp vào nhóm tử vong, còn lại được xếp vào nhóm sống.

\section{KẾT QUẢ NGHIÊN CỨU}

Nghiên cứu thu được 238 trường hợp sinh non có tuổi thai từ $28^{0 / 7}$ tuần đến hết $32^{0 / 7}$ tuân, gồm 134 trẻ trai và 104 trẻ gái. Tỷ lệ tử vong sơ sinh sớm là 4,62\% (11/238 ca)

3.1. Đặc điểm chung trẻ sơ sinh. Trong số 238 trường hợp nghiên cứu, 11 trẻ có thời gian sống dưới 7 ngày được xếp vào nhóm tử vong và 227 trẻ được xếp vào nhóm sống. Trẻ nhe cân nhất $600 \mathrm{~g}$ có tuổi thai $28^{3 / 7}$ tuần trong khi trẻ nặng cân nhất $2500 \mathrm{~g}$ có tuổi thai $30^{1 / 7}$ tuần, tất cả đều nằm trong nhóm sống.

11 trẻ trong nhóm tử vong đều có cân nặng < $1500 \mathrm{~g}$. Nhóm trẻ tử vong có cân nặng lúc sinh thấp hơn nhóm sống (1063g so với 1381g) và sự khác biệt có ý nghĩa thống kê $(p=0,000<0,05)$.

Bảng 1. Đăc điểm trẻ sơ sinh theo nhóm tử vong và sống

\begin{tabular}{|c|c|c|}
\hline Đặc điểm & $\begin{array}{c}\text { Tử vong } \\
\text { n (\%) }\end{array}$ & $\begin{array}{l}\text { Sống } \\
\text { n (\%) }\end{array}$ \\
\hline \multicolumn{3}{|c|}{ Tuối thai lúc sinh (tuần) } \\
\hline $28^{0 / 7}-28^{6 / 7}$ & $3(27,27)$ & $39(17,18)$ \\
\hline $29^{0 / 7}-29^{6 / 7}$ & $3(27,27)$ & $44(19,38)$ \\
\hline $30^{0 / 7}-30^{6 / 7}$ & $3(27,27)$ & $54(23,79)$ \\
\hline $31^{0 / 7}-31^{6 / 7}$ & $2(18,19)$ & $73(32,16)$ \\
\hline $32^{0 / 7}$ & 0 & $17(7,49)$ \\
\hline \multicolumn{3}{|c|}{ Cân nặng trẻ (gam) } \\
\hline$<1000$ & $2(18,18)$ & $13(5,73)$ \\
\hline $1000-1499$ & $9(81,82)$ & $121(53,30)$ \\
\hline $1500-1999$ & 0 & $86(37,89)$ \\
\hline $2000-2499$ & 0 & $6(2,64)$ \\
\hline$\geq 2500$ & 0 & $1(0,44)$ \\
\hline $\begin{array}{l}\text { Cân năng trung } \\
\text { bình (gam) } \\
\text { (tối thiểu - tối đa) }\end{array}$ & $\begin{array}{c}1063,64 \pm \\
162,93 \\
(800-1400)\end{array}$ & $\begin{array}{c}1381,06 \pm \\
310,36 \\
(600-2500)\end{array}$ \\
\hline Tống & $11(100,00)$ & $227(100,00$ \\
\hline
\end{tabular}




\section{2. Đăc điểm trẻ tử vong sơ sinh sớm 3.2.1. Thời gian sông}

6

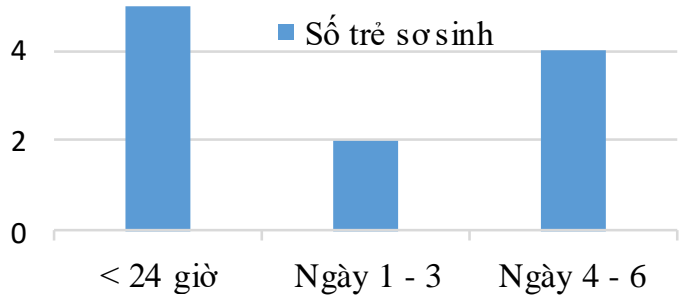

Biểu đồ 1. Phân bố về thời gian sống của nhóm trẻ tử vong

Phần lớn trẻ tử vong trong 24 giờ đầu tiên (5/11, chiếm 45,45\%).

227 trẻ trong nhóm sống qua tuần đầu tiên khi theo dõi tiếp đến hết 1 tháng tuổi có thêm 3 trường hợp tử vong sơ sinh vì nhiễm khuẩn sơ sinh và xuất huyết não - màng não.

\subsubsection{Nguyên nhân tử vong}

Trong nghiên cứu chúng tôi sắp xếp nguyên nhân tử vong mang tính chất tương đối, dựa vào triệu chứng nổi trội nhất. Hơn một nửa nhóm trẻ rất non trong nghiên cứu tử vong vì suy hô hấp (55\%). Nhiễm khuẩn và xuất huyết não - màng não cùng là lý do phổ biến thứ hai dẫn tới tử vong của trẻ.

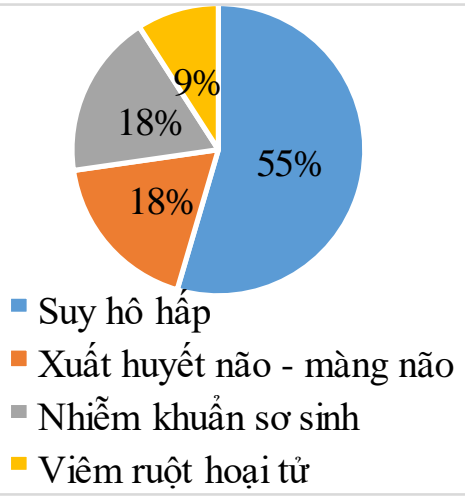

Biểu đồ 2. Nguyên nhân tử vong

3.3. Mối liên hệ giữa các yếu tố sản khoa và tử vong sơ sinh sớm

Bảng 2. Mối liên hê giữa me bênh lý và tử vong sơ sinh sớm

\begin{tabular}{|c|c|c|c|}
\hline $\begin{array}{c}\text { Yếu tố liên } \\
\text { quan }\end{array}$ & $\begin{array}{c}\text { Tử vong } \\
\text { n (\%) }\end{array}$ & $\begin{array}{l}\text { Sống } \\
\text { n (\%) }\end{array}$ & \begin{tabular}{|c} 
OR (KTC \\
$95 \%)$
\end{tabular} \\
\hline $\begin{array}{c}\text { Mẹ bếnh } \\
\text { lý* } \\
\text { Có } \\
\text { Không }\end{array}$ & $\begin{array}{l}9(81,82) \\
2(18,18)\end{array}$ & $\begin{array}{c}82(36,12) \\
145(63,88)\end{array}$ & $\begin{array}{c}7,96(1,68 \\
-37,71)\end{array}$ \\
\hline $\begin{array}{l}\text { Rối loạn } \\
\text { huyết áp }\end{array}$ & $6(54,55)$ & $36(15,86)$ & $6,37(1,84$ \\
\hline
\end{tabular}

\begin{tabular}{|c|c|c|c|}
\hline $\begin{array}{c}\text { Có } \\
\text { Không }\end{array}$ & $5(45,45)$ & $191(84,14)$ & $-21,98)$ \\
\hline \multicolumn{4}{|c|}{ Thai chậm phát triến trong tử cung } \\
\hline $\begin{array}{c}\text { Có } \\
\text { Không }\end{array}$ & $6(54,55)$ & $27(11,89)$ & $8,89(2,54$ \\
\hline Tổng & $\mathbf{1 1}$ & $200(88,11)$ & $-31,12)$ \\
\hline $\mathbf{( 1 0 0 , 0 0 )}$ & $\mathbf{2 2 7}$ & \\
\hline
\end{tabular}

*Tăng huyết áp, tiền sản giật, nhiềm trùng ối, u xơ tử cung, thiếu máu nặng

9/11 trẻ tử vong sơ sinh sớm (chiếm 81,82\%) có me mắc ít nhất môt bênh lý nội khoa hoặc sản khoa, yếu tố này làm tăng khả năng trẻ tử vong sớm gấp gần 8 lần so với trẻ cực non nhưng có me khỏe mạnh (OR = 7,96, KTC 95\% $1,68-37,71)$. Cụ thể nếu sản phụ có rối loạn huyết áp làm tăng khả năng tử vong của trẻ gấp 6,3 lần $(\mathrm{OR}=6,37, \mathrm{KTC} 95 \% 1,84-21,98)$. Đồng thời thai chậm phát triển trong tử cung cũng là một trong các yếu tố làm tăng khả năng tử vong sớm trong thời kỳ sơ sinh lên gần 9 lần $(\mathrm{OR}=8,89$, KTC $95 \% 2,54-31,12)$. Tất cả sự ảnh hưởng trên đều có ý nghĩa thống kê trong nghiên cứu này.

Bảng 3. Môi liên hệ giữa các yêu tố sản khoa khác và tử vong sơ sinh sớm

\begin{tabular}{|c|c|c|c|}
\hline $\begin{array}{c}\text { Yếu tố liên } \\
\text { quan }\end{array}$ & $\begin{array}{c}\text { Tứ vong } \\
\text { n (\%) }\end{array}$ & $\begin{array}{l}\text { Sống } \\
\text { n (\%) }\end{array}$ & $\begin{array}{c}\text { OR (KTC } \\
95 \%)\end{array}$ \\
\hline $\begin{array}{c}\text { Liệu pháp } \\
\text { corticoid } \\
\text { Có } \\
\text { Không }\end{array}$ & $\begin{array}{l}3(27,27) \\
8(72,73)\end{array}$ & $\begin{array}{l}86(37,89) \\
141(62,11)\end{array}$ & $\left\{\begin{array}{c}0,62(0,16 \\
-2,38)\end{array}\right.$ \\
\hline $\begin{array}{c}\text { Giới tính trẻ } \\
\text { Trai } \\
\text { Gái }\end{array}$ & $\begin{array}{l}7(63,64) \\
4(36,36)\end{array}$ & $\begin{array}{l}127(55,95) \\
100(44,05)\end{array}$ & $\left\{\begin{array}{c}1,38(0,39 \\
-4,84)\end{array}\right.$ \\
\hline $\begin{array}{c}\text { Cách sinh } \\
\text { Mổ lấy thai } \\
\text { Đẻ đường âm } \\
\text { đạo }\end{array}$ & $\begin{array}{l}9(81,82) \\
2(18,18)\end{array}$ & $\begin{array}{c}135(59,47) \\
92(40,53)\end{array}$ & $\begin{array}{c}3,07(0,65 \\
-14,52)\end{array}$ \\
\hline Tổng & $\begin{array}{c}11 \\
(100,00)\end{array}$ & $\begin{array}{c}227 \\
(100,00)\end{array}$ & \\
\hline
\end{tabular}

Bảng 3 liệt kê các yếu tố khác có tác động đến khả năng sống sót của trẻ tuy nhiên không có ý nghĩa thống kê với số liệu của nghiên cứu này.

Có duy nhất liệu pháp corticoid là yếu tố bảo vệ khi làm giảm khả năng tử vong so với nhóm không dùng corticoid ( $\mathrm{OR}=0,62$, KTC $95 \%$ 0,16 $-2,38)$.

Trong nghiên cứu nói chung và nhóm tử vong nói riêng, số trẻ trai nhiều hơn số trẻ gái. Giới nam làm tăng khả năng tử vong sơ sinh sớm $38 \%(\mathrm{OR}=1,38$, KTC $95 \% 0,39-4,84)$.

Mổ lấy thai cũng là yếu tố làm tăng khả năng tử vong trong nghiên cứu này $(\mathrm{OR}=3,07, \mathrm{KTC}$ $95 \% 0,65-14,52)$. 


\section{BÀN LUÂNN}

4.1. Đăc điểm chung trẻ sơ sinh. Cân nặng khi sinh thấp và trẻ non tháng là những đặc điểm quan trọng nhất vì cả hai yếu tố làm nặng thêm toàn trạng của trẻ sơ sinh và góp phần gây tử vong sớm. Nghiên cứu của chúng tôi với số liệu chưa đủ lớn, không nhận thấy sự khác biệt có ý nghĩa thống kê về tiên lượng sống sót giữa các nhóm cân nặng và các nhóm tuổi thai ( $p>0,05$, test Fisher). Trương Quang Hưng và cộng sự (2018) cũng thực hiện nghiên cứu bệnh chứng trên trẻ đẻ non tuổi thai 28 đến 32 tuần và nhận thấy cân nặng có ảnh hưởng có ý nghĩa thống kê lên khả năng sống trong 7 ngày sau sinh, với sự khác biệt ở nhóm < $2500 \mathrm{~g}$, < $1500 \mathrm{~g}$ và $<1000 \mathrm{~g}(\mathrm{p}=0,0001)$ [3]. Dương Thanh Long và cộng sự nghiên cứu trên 207 trẻ dưới 28 ngày tuổi đã chỉ ra cân nặng lúc sinh < $1500 \mathrm{~g}$ làm tăng khả năng tử vong 7 lần $(\mathrm{OR}=$ 7,1, KTC 95\% 2,2 - 22,9) [4].

\section{2. Đặc điểm trẻ tử vong sơ sinh sớm}

4.2.1. Thời gian sống. Nghiên cứu của chúng tôi cũng nhận thây tử vong sơ sinh ở trẻ non tháng chủ yểu xảy ra trong 24 giờ đầu, tương tự như nhận định chung của Tổ chức $\mathrm{Y}$ tế Thế giới WHO và nhiều nghiên cứu trong và ngoài nước. Tỷ lệ này dao động từ $45,5 \%$ đến $80,4 \%$ [2], [4], [5], [6].

4.2.2. Nguyên nhân tử vong. Hội chứng suy hô hấp là rối loạn hô hấp phổ biến nhất ở trẻ đẻ non và tỷ lệ mắc có liên quan trực tiếp đến mức độ đẻ non [1], [2]. Nghiên cứu của Trần Diệu Linh và cộng sự cũng tại Bệnh viện Phụ sản Trung ương năm 2013 chỉ ra bệnh lý hô hấp là nguyên nhân hàng đầu gây tử vong ở trẻ đẻ non nhe cân $(54,3 \%)$ và xuất huyết não - màng não là nguyên nhân đứng thứ hai $(26,4 \%)$ [5]. Trong khi đó Dương Thanh Long và cộng sự nhận thấy các bệnh thường gây tử vong sơ sinh là bệnh màng trong $(50 \%)$, nhiễm khuẩn huyết $(13 \%)$ và ngat $s \sigma$ sinh $(8,7 \%)$ [4].

4.3. Mối liên hệ giữa các yếu tố sản khoa và tử vong sơ sinh sớm. Trẻ nhe cân, hoặc có tình trạng chậm phát triển trong tử cung cũng là một trong những yếu tố tiên lượng xấu đến khả năng sống của trẻ đẻ non. Một nghiên cứu tại Bangladesh chỉ ra nguy cơ tử vong ở nhóm trẻ đẻ non gấp 7 lần nhóm trẻ đủ tháng cùng có chậm phát triển trong tử cung ( $R R=4,78, \mathrm{KTC}$ $95 \% 3,14-7,27)[7]$.

Tổng quan hê thống Cochrane của Roberts cho thấy liệu pháp corticosteroid trước sinh làm giảm $31 \%$ nguy cơ tử vong sơ sinh $(R R=0,69$, KTC $95 \% \quad 0,59-0,81$ ) và giảm $34 \%$ nguy cơ mắc hội chứng suy hô hấp $(R R=0,66, \mathrm{KTC} 95 \%$ $0,56-0,77)$ [8]. Do đó, corticosteroid đã được đưa vào khuyến cáo lâm sàng của nhiều hiệp hội, chuyên ngành [1]. Chúng tôi cũng thu được kết quả tương tự như trên.

Nghiên cứu về ảnh hưởng giới tính lên khả năng sống sót của trẻ sinh non của chúng tôi cho thây giới nam làm tăng khả năng tử vong $(\mathrm{OR}=1,38, \mathrm{KTC} 95 \%$ 0,39 - 4,84). Một phân tích dữ liệu trong 8 năm từ 2010 đến 2018 tại hai nước Ấn Độ và Pakistan cũng cho thây tỷ lệ tử vong sơ sinh nói chung ở trẻ nam cao hơn có ý nghĩa thống kê (33,2/1000 trẻ đẻ sống) so với trẻ nữ $(27,4 / 1000, p<0,001)$. Tỷ lệ tử vong sơ sinh sớm ở nam cũng cao hơn $(27,1$ so với $21,6 / 1000$ trẻ đẻ sống) [6]. Điều này cũng giống với nghiên cứu của chúng tôi và các nghiên cứu trong nước [3], [4], [5].

Mổ lấy thai có thể coi là một cách sinh an toàn đối với thai non tháng, đặc biệt khi tỷ lệ ngôi bất thường (mông/vai) cao hơn ở tuổi thai nhỏ khiến cuộc đẻ đường âm đạo có nhiều nguy cơ hơn [1]. Nghiên cứu của Lee và Gould trên trẻ nhe cân hoăc trẻ có chậm phát triển trong tử cung có tuổi thai 26 - 30 tuần chỉ ra nếu được mổ lấy thai sẽ có lợi nhiều hơn, bởi giảm sang chấn không cần thiết khi đẻ đường âm đạo lên nhóm nguy cơ cao này [9]. Tuy nhiên nghiên cứu của chúng tôi lại cho kêt quả ngược lại. Điều này có thể giải thích bởi số lượng trẹ̉ thu thập không nhiều, có sự chênh lệch quá lớn giữa hai nhóm đẻ đường âm đạo và mổ lấy thai.

\section{KẾT LUÂ̂N}

Tỷ lệ tử vong sơ sinh sớm ở nhóm trẻ đẻ non 28 - 32 tuần là $4,62 \%$, trong đó phần lớn tử vong trong 24 giờ đâu tiên (45,45\%). Nguyên nhân thường gặp là suy hô hấp (55\%), nhiễm khuẩn $(18 \%)$ và xuất huyết não - màng não $(18,8 \%)$.

Mẹ bệnh lý (đăc biệt rối loạn huyết áp) và thai chậm phát triển trong tử cung là các yếu tố làm tăng nguy cơ tử vong sơ sinh sớm của trẻ.

\section{TÀI LIÊU THAM KHẢO}

1. Nguyễn Viết Tiến (2012), Sản phụ khoa - Bài giảng cho hoc viên sau đai học, Nhà xuất bản $Y$ hoc.

2. Guevvera Y. (2006). World Health Organisation: Neonatal and perinatal mortality: country, regional and global estimates. WHO cebu: sun.

3. Trương Quang Hưng (2018). Khảo sát các yếu tố liên quan đên nguy cơ tứ vong sơ sinh sớm của trẻ ở tuổi thai 28 - 32 tuần tại Bệnh viện Hùng Vương. Tạp chí Y học TP Hồ Chí Minh, 22(1) 49.

4. Dương Thanh Long (2012). Đánh giá các yếu tố nguy cơ gây tữ vong sơ sinh tại khoa Nhi Bệnh viện ĐKTT An Giang 2010 - 2011. Kỷ yếu Hội nghị Khoa học Bệnh viện An Giang, 203. 
5. Trân Diệu Linh, Lê Anh Tuấn, and Phan Thị Thu Nga (2013). Nghiên cứu tình hình bệnh lý và tử vong tré sơ sinh non tháng - thấp cân tại Bệnh viện Phụ sản Trung ương năm 2010. Tạp chí P̉hụ sản, 11(2), 65-69.

6. Aghai Z.H., Goudar S.S., Patel A., et al. (2020). Gender variations in neonatal and early infant mortality in India and Pakistan: a secondary analysis from the Global Network Maternal Newborn Health Registry. Reprod Health, 17(3), 178.
7. Yasmin S., Osrin D., Paul E., et al. (2001). Neonatal mortality of low-birth-weight infants in Bangladesh. Bull World Health Organ, 79(7), 608-614.

8. Roberts D., Brown J., Medley N., et al. (2017). Antenatal corticosteroids for accelerating fetal lung maturation for women at risk of preterm birth. Cochrane Database Syst Rev, 3, CD004454.

9. Lee H.C. and Gould J.B. (2006). Survival rates and mode of delivery for vertex preterm neonates according to small- or appropriate-for-gestationalage status. Pediatrics, 118(6), e1836-1844.

\section{XÂY DỰNG MÔ HÌNH PHÂN TÍCH TÁC ĐộNG NGÂN SÁCH RUXOLITINIB TRONG ĐIỀU TRỊ XO' TỦY NGUYỀN PHÁT TẠI VIỆT NAM}

\section{TÓM TẮT}

Xơ tủy nguyên phát (XTNP) là bênh lý huyết học được tiên lượng điều trị bất lợi nhất trong nhóm bệnh tăng sinh tủy ác tính. Thuốc ruxolitinib (RUX) được chứng minh làm giúp giảm thể tích lách và nguy cơ tử vong so với tri liêu tốt nhất hiên có (Best available therapy - BAT) trong điêu trị XTNP. Với giá thành thuốc cao, cần thiết phải xem xét tính khả thi khi lựa chọn thuốc trong thực hành lâm sàng dựa trên phẩn tích tác động ngân sách (TĐNS), trong đó xây dựng mô hình đánh giá TĐNS được xem là một trong những bước quan trọng quyết định tính khả thi và độ tin cậy của nghiên cứu. Với phương pháp mô hình hóa kết hợp với tổng quan tài liệu và tham vấn ý kiến các chuyên lâm sàng, nghiên cứu đã xây dựng được mô hình đánh giá TĐNS RUX trong điều trị XTNP tại Việt Nam trên nền tảng phần mềm MS Microsoft Excel 2013 với cấu trúc mô hình bao gồm các trang tính toán cho các Tham số đâu ra (tác đônng ngân sách và hiệu quả) cho 2 viễn cảnh không có RUX và có RUX. Mổ hình được xây dựng cho phép phân tích tác động ngân sách của RUX với các mức thanh toán bảo hiểm y tế khác nhau trong điều trị xơ tủy nguyên phát cũng như dư báo được tác động trong hiệu quả điều trị giữa hai viê̂n cảnh nghiên cứu.

Tư khóa: Phân tích tác động ngân sách, ruxolitinib, xơ tủy nguyên phát, mô hình.

\section{SUMMARY \\ CONSTRUCT THE MODEL OF BUDGET IMPACT ANALYSIS OF RUXOLITINIB IN PRIMARY MYELOFIBROSIS IN VIETNAM}

Primary myelofibrosis (PMF) is the hematologic disease which has the most unfavorable prognosis in

*Đai hoc Y Dược Thành phố Hồ Chí Minh Chịu trách nhiệm chính: Nguyễn Thị Thu Thủy Email: nguyenthuthuy@ump.edu.vn Ngày nhận bài: 7.6.2021

Ngày phản biện khoa học: 2.8.2021

Ngày duyệt bài: 12.8.2021
Nguyễn Gia Bảo*, Nguyễn Thị Huệ*, Hoàng Kim Trúc*, Nguyễn Thị Thu Thủy*

the group of myeloproliferative neoplasms diseases. Ruxolitinib (RUX) has been shown to significantly reduce spleen volume and risk of death compared with the best available therapy (BAT) in PMF treatment. With high drug costs, it is necessary to consider the feasibility of drug selection in clinical practice based on budget impact analysis (BIA), in which constructing model is considered one of the most important steps, deciding the feasibility and reliability of BIA. With modeling research method combined with literature review and indepth-interview with clinical experts, the BIA model has been built based on MS Microsoft Excel 2013 software with model structure including calculation pages for outcome parameters (budget impact and effectiveness impact) for 2 scenarios without RUX and with RUX. The model allows to conduct BIA of RUX with different health insurance payments in PMF as well as evaluate the effectiveness impact of treatment between the two research scenarios.

Keywords: Budget impact analysis, ruxolitinib, primary myelofibrosis, model

\section{I. ĐĂT VẤN ĐỀ}

Xơ tủy nguyên phát (XTNP) là bệnh lý huyết học được tiên lượng điều trị bất lợi nhất trong nhóm bệnh tăng sinh tủy ác tính ${ }^{1}$. Do đó, chí phí điều trị XTNP đang ngày càng trở thành gánh nặng. RUX là chất ức chế JAK1/JAK2 được chứng minh làm giảm thể tích lách và nguy cơ tử vong so với trị liệu tốt nhất hiện có (BAT - Best available therapy) thông qua nghiên cứu COMFORT- II trong điêu trị XTNP2,3. Với giá thành thuốc cao, cân thiết phải xem xét tính khả thi khi lựa chọn thuốc trong thực hành lâm sàng dựa trên phân tích tác động ngân sách (TĐNS). Măc dù nhiều nghiên cứu phân tích TĐNS đã được tiến hành trên thế giới ${ }^{4}$ tuy nhiên chưa có nghiên cứu được tiến hành tại Việt Nam. Hơn thế nữa, để thực hiện phân tích TĐ̣S một trong những công cụ quan trọng là xây dựng mô hình 